\title{
Research on landscape design of rural linear space-CTaking the design of Haiou Island Rural pedestrian street as an example
}

\author{
ZhongWeiWang ${ }^{1, *}$, ZhaomingDu$^{2}$, PengnanLi ${ }^{3}$ \\ ${ }^{1}$ School of art and design, Guangdong University of Finance \& Economics, Guangzhou, China \\ ${ }^{2}$ School of art and design, Guangdong University of Finance \& Economics, Guangzhou, China \\ ${ }^{3}$ School of art and design, Guangdong University of Finance \& Economics, Guangzhou, China
}

\begin{abstract}
Based on the rural regional characteristics, this paper analyzes the types and characteristics of linear space, and discusses the landscape design strategies of rural linear space in the context of territoriality. Specifically, it explores the landscape design path of rural linear space through spatial sequence fabric, detail context narrative, local materials and technology vocabulary application, and takes the landscape design of Haiou Island Rural pedestrian street as an example to do a further practical demonstration.
\end{abstract}

\section{Overview of rural linear space}

In the field of place space, linear space refers to the narrow and long banded space form formed by the strong directivity of space in a certain direction. Any space with obvious unidirectional dominance can be called linear space. In the rural space, there are three types of linear characteristics: street space, shoreline space and corridor space. According to the changes of the location and scale of street and shoreline, different structural relationships are formed with the main body of the building (table 1), the street includes several levels of main street, alley and lane. Rural linear space connects the village square, street node, construction group and courtyard. By creating its boundary transition space and improving its publicity, the integration of functional units under the original order of settlement can be realized. The landscape design of linear space helps to strengthen the regional characteristics and landscape features of settlement space.

Table1. Analysis of the relationship between buildings, streets, rivers and roads

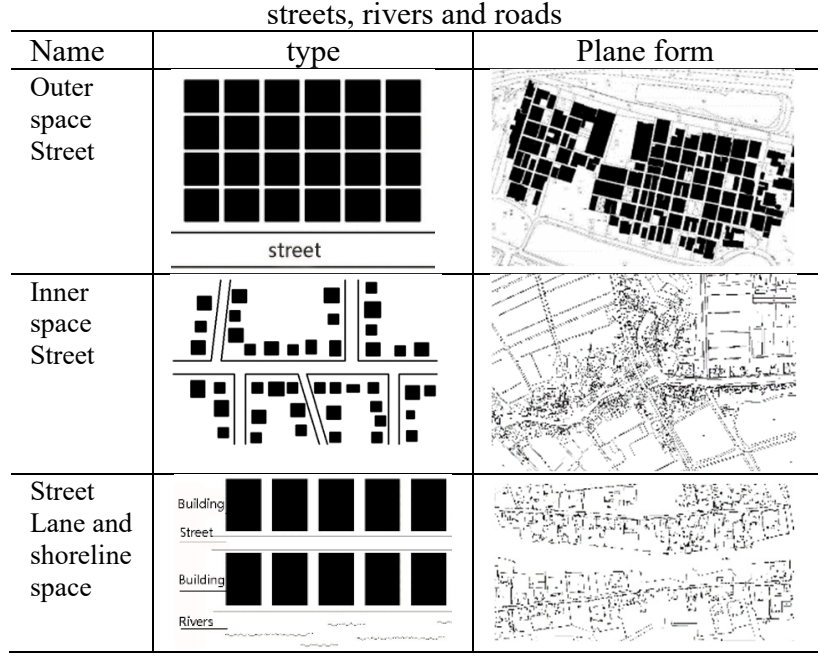

\section{The construction strategy of rural linear space}

\subsection{The integrity and variability of linear space sequence}

Linear space is the pattern of group consciousness generated by imitating and adjusting the paradigm under the self-organization state of the village subject. Therefore, the linear space design should pay attention to the balance of its integrity and variability, so as to effectively weaken the disadvantages of monotonous space. The design applies the construction method of paragraph sequence. Firstly, set the overall style orientation and construction mode, and then segment the suitability of the zonal space. According to the differences between the site landscape and the architectural interface, the corresponding theme is established, and the characteristics of each section under the overall unity are shaped, so as to eliminate the boredom of the long zonal space. For example, group construction of important common nodes in linear space belt can form multiple spatial attraction points; Or take the old buildings as the center, together with the surrounding houses and courtyards to construct the landscape group with regional characteristics, and combine the corridors to connect multiple groups, with the radiation force and attraction of spatial clusters, the integration of functional units and style coordination under the original order of the place can be realized (Fig. 1), thus enhancing the features and sequence changes of the stage space.

\footnotetext{
* Corresponding author e-mail: 20191059@gdufe.edu.cn
} 


\subsection{Narrative expression of memory context in linear space}

There are a lot of memory places in the settlement space. In the construction of linear space, we should actively explore the cultural information of historical memory, and form the context narrative expression and aesthetic experience of homesickness of each space point. For example, the village entrance space in the linear space paragraph, the intermediary space between houses, which contains a large number of historical sites and story settings, through the ritual narrative writing of these point space, strengthen its identifiability, explain the life memory information. On the one hand, it can continue the derivative relationship between history and modern through the renewal of structures or landscape heritage; on the other hand, it can generate local cultural images through the patterned construction of local detail materials, and gradually establish the narrative expression with nostalgia aesthetic feelings.

\subsection{Ruralization and ecological landscape construction}

" Ruralization " is an important feature of rural aesthetics which is different from urban aesthetics. It is reflected in the low cost and saving of rural landscape and the shaping of local characteristics. Local construction focuses on the use of local materials, low-tech construction methods and local design combined with local technology, and the design process of integrating materials, structure and construction; In addition to the emphasis on the protection of local environment and the application of local materials, "ecologization" actively introduces modern ecological technology to promote the formation of new forms and new functional places of local landscape. The upgrading of vernacular landscape first presents the characteristics of "ecological adaptation, repairing the old from the abandoned". Drawing lessons from the grassroots and spontaneous characteristics of rural construction, it pays attention to the reuse of vernacular materials and wastes. On the other hand, it pays attention to the combination of process standardization and localization. The effective application of modern technology can make up for the shortcomings of traditional technology and improve the design effect and efficiency, It provides support for the framework and construction method of open and elastic space.

\section{Landscape planning and design of Haiou Island Rural pedestrian street}

\section{1 location background and current situation analysis}

Haiou island is located in the eastern suburb of Panyu District, Guangzhou, and the east of Shilou town. It is located at the estuary of the Pearl River and faces the lion ocean. It is a typical inland river island which is surrounded by the main channel of the Pearl River and Lianhuashan road.formed by the alluvial rivers of the
Pearl River Delta. The 13 kilometer seagull road runs through the island from north to south. The island is mainly engaged in planting and breeding, and the main crops are rice, bananas, flowers and so on. It is a unique green ecological island in the urban community of the Pearl River Delta. The project is located in the east side of Haixin section of Haiou Island Haiou Road, Shilou Town, Panyu District, Guangzhou City, reaching the lower bridge site of Haiou bridge in the north and the section at the junction of four lanes and two lanes of Haiou road in the south, with a distance of about $1.3 \mathrm{~km}$. Haixin road section is located at the foot of Haiou bridge. At present, it is the only way to get in and out of Haiou Island, with vegetable market, fruit farm and Qifeng farm on both sides. Therefore, the government has built this road section into a rural commercial pedestrian street, so as to further improve the environmental appearance of Haiou Island entrance and exit, and promote the ecological environment construction and economic and social development of Haiou island.

The reconstruction site is the East and west sides of a highway, belonging to the peripheral part of Haixin village of Haiou island. Haixin village belongs to DanJia cultural village. The early buildings include red brick houses, gray sand houses, etc. the buildings are mostly decorated with concrete flowers and glazed flowers. Nowadays, in the context of rapid urbanization, the buildings on both sides of the street have become 3 to 4 floors tile houses built by residents themselves. The first floor is usually used as shops, with a more modern architectural style, and the surrounding environment is in a state of disordered spontaneous construction. The whole building interface forms an open space distance of about 20 meters from the highway, and forms a terrain elevation difference of about 1 meter from the building to the highway. The original open space is cement ground, the boundary between the site and the road is not clear, the parking on the site is chaotic, and there are potential safety hazards for vehicles entering and leaving (Fig.1). Secondly, all kinds of plants are planted disorderly in the site, and there are all kinds of temporary structures in some parts, which seriously affect the overall landscape on both sides of the road. Third, the information of shops along the street is messy, which makes it difficult to form an overall intuitive main interface. Therefore, this design is mainly faced with the problem of site function rectification, and how to realize the construction of the local style sequence of the landscape pedestrian road on both sides.

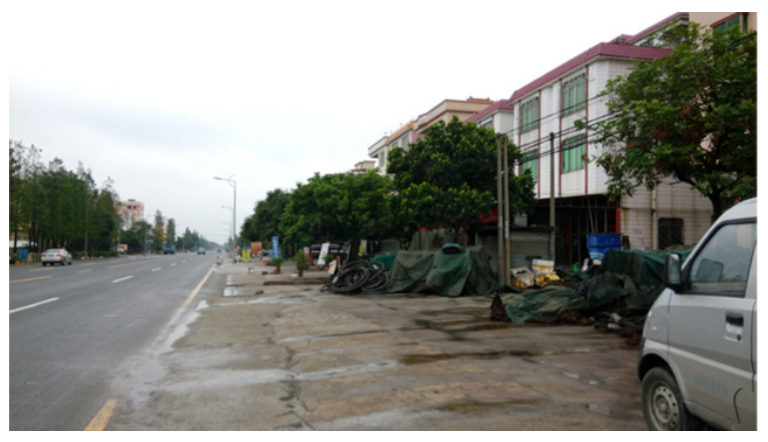

Figure 1. Current situation of original site 


\subsection{Planning and design}

\subsubsection{Planning concept}

In order to reflect the local characteristics of the region, effectively rectify the disorder of the original place and the lack of obvious style and features as the goal, combined with peripheral business fundamentals, build a commercial business area with rural vitality and characteristics. Based on the linear spatial characteristics of the site, the planning divides the site into five sections according to the location of streets and alleys in the way of paragraph construction (Fig.2), and each section makes characteristic theme changes in the aspects of flower pool modeling, detail decoration, road pavement and planting, so as to enrich the spatial content in a single pattern and form the characteristic changes among each section under the overall style.

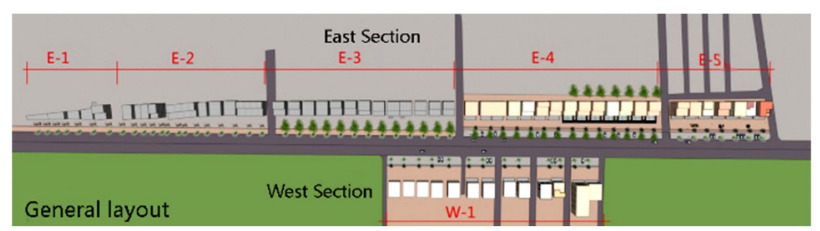

Figure 2. General layout (source: drawing by author)

\subsubsection{Function planning and diversion of people and vehicles}

Using the height difference of nearly one meter at the beginning of the original site, the design steps divide the site into three functional levels: commercial recreation area, parking area and peripheral footpath area. The three areas are divided by the red brick pool as the boundary, supplemented by steps to connect, forming the separation of people flow and traffic flow of Commercial Recreation (Fig.3). The commercial recreation is divided into two parts: corridor footpath and peripheral footpath, forming the inner and outer space changes of streets. At the same time, it is clear that the original disordered green planting, corresponding to the space of about 1 meter between each house, is planted with local trees, forming the counterpoint relationship of different tree species in front of the house, which can not only create a green atmosphere of the site, but also strengthen the sense of order in the space sequence of the site (fig. 4).

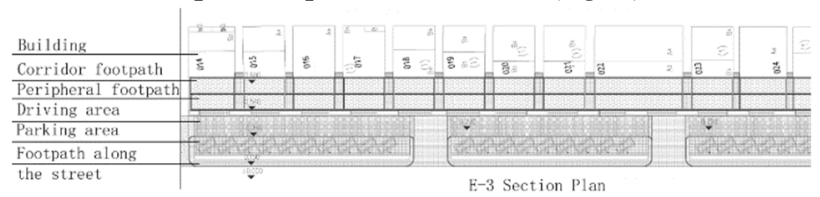

Figure 3. local plan (source: drawing by author)



Figure 4. Section (source: drawing by author)

\subsubsection{Walking space and overall image}

In view of the strong light, hot and humid climate in Lingnan area, residents like to be ventilated and cool. Referring to the image characteristics of Guangzhou style arcade commercial street, a steel structure scaffolding with a span of 4 meters is overhanging according to the building. The front end is supported by a galvanized cross steel frame, the outside is embedded with $4 \log$ squares (bolted), and the foundation is made of precast concrete piles (Figures 7 and 8). The "purlin" and "rafter" of the framework are laid with galvanized steel pipe, and the steel pipe is used as the transverse connection "beam" between the columns to make the overall structure stable. The scaffolding is decorated with anti-corrosion wood, the cornice is closed with aluminum alloy edging, and the metal with local pattern is hung under the external cornice. The inside of the eaves buckle is tested and designed with stretchable bamboo curtain to shade (FIG. $10,11)$. The roof is made of aluminum alloy roof panel, creating a commercial space with local characteristics. The integral design of the veranda constructs a unified spatial sequence for the disordered space; On the other hand, the corridor sequence is based on the forward extension of the building, and the pedestrian's line of sight is attracted by it. To a certain extent, it obscures the "modernization" of the ceramic tile house, forming the iconic style keynote of the rural pedestrian street.

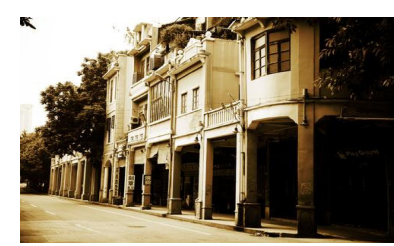

Figure 5. arcade in Guangzhou



Figure 7. space outside pedestrian street Figure

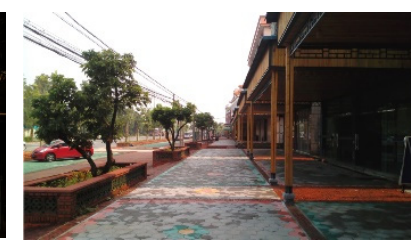

Figure 6. pedestrian street

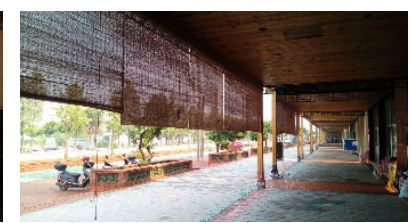

Figure 8. gray space of pedestrian street

\subsection{Narrative expression of local memory}

Local context narrative is mainly reflected in the application of local element symbols, local materials and local crafts. For example, different sections have different decorative symbol types, hang mosaic symbols on the trellises of different sections and the difference between the flower beds and the ornaments in different sections is made. The facade of the flower pond is organically combined with the elements of glazed flower, bamboo, concrete, and concrete board, etc. Create visual content and detail changes in different areas (Table2). 
Table2. flowerpot style sheet (source: photo by author)

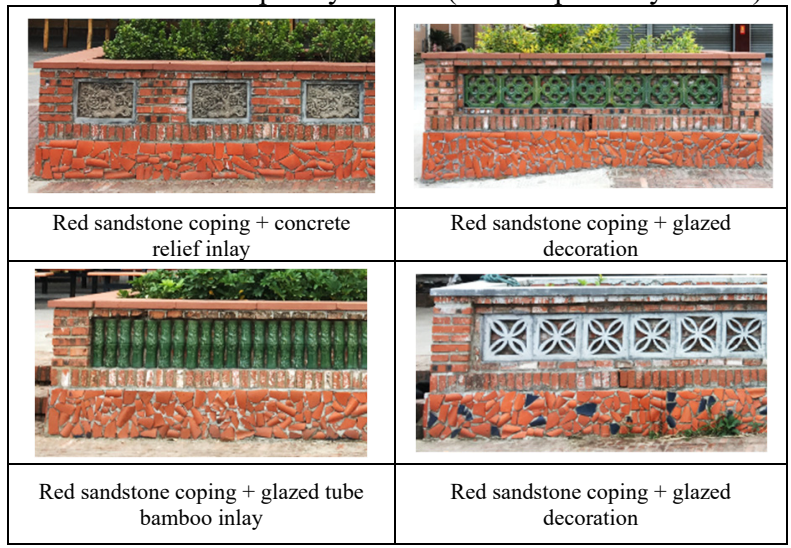

The paving materials of rural pedestrian street are mainly hexagonal bricks, with red, green and yellow colored hexagonal bricks as the central pattern, and the red and colored hexagonal bricks as the edge of the area (FIG. 9). Different color and material combinations are applied in different sections.

In the paving of red brick footpath, the method of absorbing rural soil is adopted. The red brick is built vertically without cement mortar in the middle. Only the red brick is compacted to form a plane, and the surface is sprinkled with fine sand (Fig.10). This method can make use of the gap between red bricks to form surface water infiltration, which is very conducive to pavement drainage. In terms of planting, longchuanhua, Forsythia suspensa, Rhododendron pubescens and other shrubs were planted in different sections of the inner space flower pool to strengthen the characteristics of different sections. The trees are planted with longan, a local tree species. Longan is short and will not block the store. Beautiful kapok is planted near the periphery of the road. It is tall and straight, and belongs to flowering plants. When visitors drive down the bridge, they will form their first impression of Haiou island(Fig.11-12).

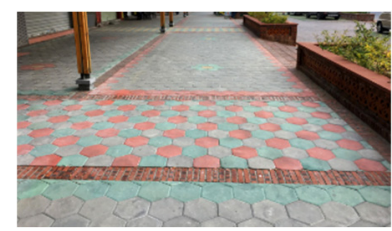

Figure 9. Floor paving with hexagonal brick

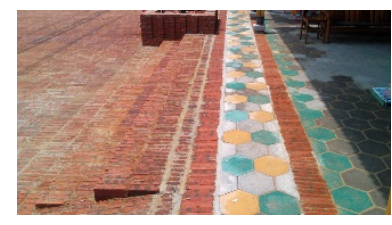

Figure 11. Paving details

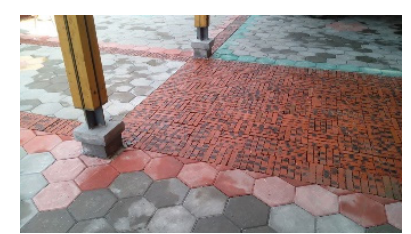

Figure 10. Hexagonal brick and red brick

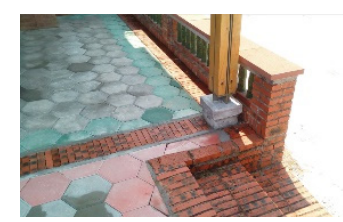

Figure 12. Paving details

\section{Summary}

Rural linear space is the main space and Interface of the countryside, which Display the most distinctive rural style.From a design point of view, we should not only consider the variability of a single linear space, but also consider the landscape expression of the aesthetic characteristics of rural linear space. A large number of material and social cultural contents in the village are comprehensive and integral. Compared with the settlement as a whole, architecture is also a part of the settlement landscape. The boundary between the two forms is vague and their functions are highly integrated. As Dr. Luo Hui said: the rural landscape environment is a combination of weak artificial and the strong nature relatively, such as the agricultural landscape of fields, fish ponds and vegetable gardens, behind them is human agriculture. Therefore, the settlement linear space design should emphasize the form interaction and function translation between architecture and landscape, and explore the symbiotic path of new rural landscape and architecture in an integrated and mixed way.

At the same time, the landscape construction integrates the standardized and modular modern technology to make up for the shortcomings of traditional technology and improve the design effect and efficiency. At the same time, the penetration of modern technology expands the openness and plasticity of the space. On the other hand, it involves the refining and innovation of regional decorative symbols, and the application of local materials and techniques. In the process of implementation, architects do not need to be strict with the control of all design details, and it is best to hand over some of the design to craftsmen or villagers: $60 \%$ $70 \%$ of the architects determine the design by themselves, $30 \%$ of them are left on the site to determine according to the opinions of craftsmen and villagers, and the construction drawings will be supplemented after the construction is completed. This mode can not only ensure that the whole architectural scheme is carried out according to the architect's ideas, ensure the basic degree of completion and style, but also set aside the possibility of "surprise" for the project according to local conditions. Because many practices come from the understanding of local craftsmen, the aesthetic perspective is quite different from the academic perspective. On the contrary, it can break through the conventional thinking and create boundaries, highlight the local aesthetic appeal.

\section{Acknowledgments}

This Paper was supported by the following Research Funds: Characteristic innovation project of Guangdong Universities in 2020:"Research on the Construction and application of landscape schema language in traditional villages of Guangfu area” (No.2020WTSCX026) ;

Key Humanities and Social Sciences projects in Guangdong universities from Education Department in 2019:"Research on Inheritance and innovation of ecological wisdom of traditional human settlements in Lingnan"(No.2019WZDXM007);

Social science project in Foshan: Research on the construction paradigm of new rural communities in Foshan (No. 2021-GJ081); 


\section{References}

1. Y. Fu, Z.C. Yu, A.C 9,100(2015)

2. A. Rapoport, House Form and culture, (China Architecture \& Building Press, Beijing, 2007)

3. ZW.Wang,Research on rural landscape construction strategies from the perspective of rural aesthetics Take villages in the Pearl River Delta area as an example,189,(2019)

4. H. Luo, C. Zhao, N.B 9, 1 (2015) 